\title{
A Combination of Two Variants p. $($ Val510 $=)$ and p. (Pro2145Thrfs * 5), Responsible for von Willebrand Disease Type 3 in a Caribbean Patient
}

\author{
1 EA 7525 VPMC, Université des Antilles, Schoelcher, Martinique, \\ France \\ 2 Ressources and Competence Center for Constitutional Hemorrhagic \\ Diseases (CRC-MHC), CHU Martinique, Martinique, France \\ ${ }^{3}$ HITh, UMR_S1176, INSERM, Université Paris-Saclay, Le Kremlin- \\ Bicêtre cedex, France \\ ${ }^{4}$ Department of Hematology and Transfusion, CHU Lille, Lille, France \\ ${ }^{5}$ Department of Medical Genetics, Hôtel-Dieu Hospital, CHU Nantes, \\ Nantes, France \\ ${ }^{6}$ Fort-de-France, CHU Martinique, Martinique, France
}

Marie Daniela Dubois ${ }^{1}$ Serge Pierre-Louis ${ }^{2}$ Johalène Rabout ${ }^{2}$ Cécile V. Denis ${ }^{3}$ Olivier Christophe ${ }^{3}$ Sophie Susen ${ }^{4}$ Jenny Goudemand ${ }^{4}$ Pierre Boisseau ${ }^{5}$ Rémi Neviere ${ }^{1,6}$ Olivier Pierre-Louis ${ }^{1}$

TH Open 2020;4:e318-e321.

von Willebrand disease (VWD) represents one of the most common inherited hemorrhagic disorders in France with 1,980 patients identified in the FranceCoag network in December 2016. ${ }^{1}$ The disease results from genetic defects generally localized in the von Willebrand factor (VWF) gene, defects that can either modify the function of the protein or affect its clearance and/or synthesis. In the French Caribbean island of Martinique, VWD prevalence in symptomatic subjects amounts to approximately $0.02 \%$ of the population. This work describes a new variant p.(Val510 =), located in the D2 domain of VWF, in Martinican's families. This variant $\mathrm{p}$. $\left(\right.$ Val510 $=$ ) associated with the variant p.(Pro2145Thrfs ${ }^{*}$ ) causes VWD type 3 (VWD3).

An informed consent for a genetic analysis and phenotypic characteristics has been signed by all the patients included in this study. The VWF gene was analyzed by next-generation sequencing in 4 members of the original family that we have identified, that is, the father (I-1), the mother (I-2), the proband (II-2), and her sister (II-1) (-Fig. 1A). The proband was a woman affected by severe hemorrhagic manifestations. Her biological profile was evocative of VWD3: VWF: $\mathrm{Ag}=1$ to $5 \%$, VWF:RCo $=5 \%, \mathrm{FVIII}: \mathrm{C}=2$ to $3 \%$, VWFpp $=6 \%$, and a total absence of multimers assessed by electrophoresis (-Fig. 1B). She was usually treated with plasma-derived VWF concentrates. Interestingly, the VWFpp level in this patient was higher than expected for typical VWD3. The sister (II-3) who died from a nonhemorrhagic cause had the same clinical-biological profile as the proband. VWF se-

received

January 15,2020 accepted after revision

September 11, 2020
Address for correspondence Marie Daniéla Dubois, MSc, EA 7525 VPMC, Université des Antilles, Schoelcher 97275, Martinique (e-mail: mariedaniela.dubois@gmail.com).

quencing revealed the presence of two causative genetic variants present in a heterozygous state ( - Fig. 1C). The first one, p.(Val510=), is a previously unreported synonymous variant present in VWF propeptide, which is frequently found in Martinique, indicating the presence of a cluster. The second one, p.(Pro2145Thrfs*5), located on exon 37 has already been described in VWD type 1 (VWD1) patients ${ }^{2}$ and leads to a shift of the reading frame and the appearance of a stop codon. In addition to these two variants, five variants/polymorphisms (p.Ala631Val, p.Met740Ile, p. His817Gln, p.Asp1472His, and p.Arg2185Gln) previously described as non- or little deleterious in healthy populations have also been detected in this patient.

We next studied the mother and the father of the proband. The mother (I-2) had a normal biological assessment (VWF: $\mathrm{Ag}=131 \%$, VWF:RCo $=116 \%$ ) and was asymptomatic without any bleeding. Sequencing of the mother's VWF gene revealed a single variant on the VWF mature subunit: the c.6432dup which results in a stop codon. This molecular abnormality described in the mother (I-2) is in favor of a status of transmitter of VWD3. The father (I-1) experienced excessive bleeding only as a result of trauma or surgery. Sequencing of the father's VWF gene led to the identification of one potential causative variant: p.(Val510=), and five polymorphisms previously identified in healthy individuals. The phenotype reported by the father is of particular interest as biological assays did not report any dissociation between VWF:RCo (10\%) and VWF:Ag (12\%), suggestive of VWD1

\footnotetext{
(c) 2020 Georg Thieme Verlag KG Stuttgart · New York
}

License terms

10.1055/s-0040-1718703. ISSN 2512-9465.

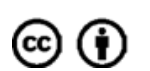


A

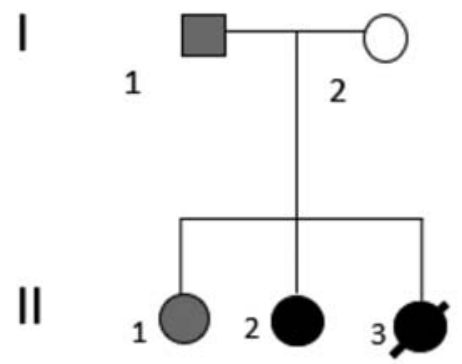

B

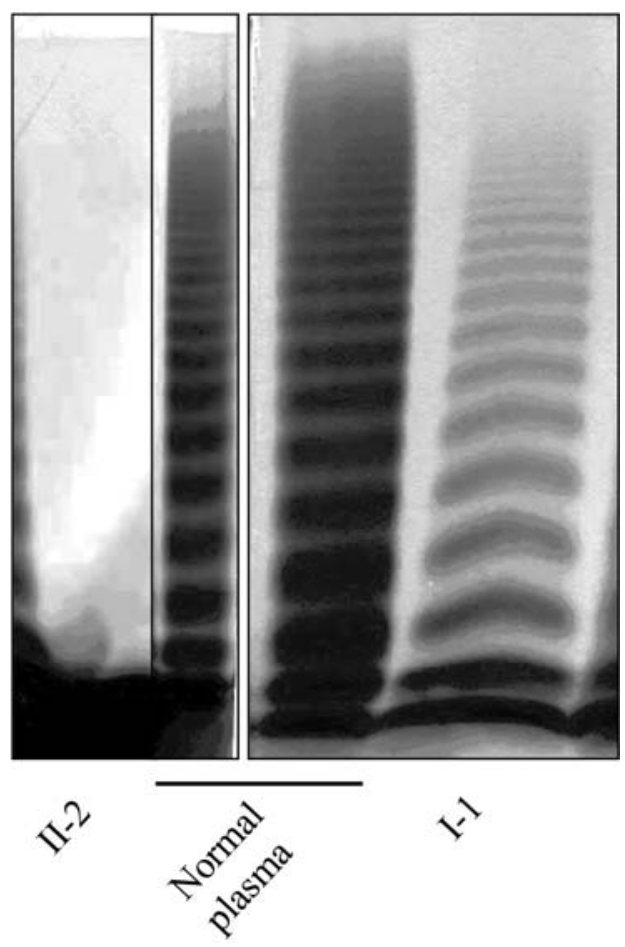

C

\begin{tabular}{ccccc} 
Variant type & Location & Domain & $\begin{array}{c}\text { Nucleotide } \\
\text { Change }\end{array}$ & Amino acid change \\
\hline missense & exon 13 & D2 & c.1530G $>A$ & p.(Val510=) \\
duplication & exon 37 & D4 & c.6432dup & p.(Pro2145Thrfs*5) \\
\hline
\end{tabular}

Fig. 1 Presentation of a Martinican family with von Willebrand disease (VWD). (A) Proband II-2 genealogical tree. White symbol: VWD type 3 (VWD3) transmitter; gray symbol: patients VWD with p. $($ Val510 =). (B) von Willebrand factor (VWF) multimer analysis in plasma from the proband (II-2) and her father (I-1). (C) Molecular analysis of the VWF gene of the proband by next-generation sequencing (NGS) IDT Sequencing.

whereas the study of plasma VWF multimers showed a significant and uniform reduction in the percentage of high molecular weight forms and intermediate molecular weight forms (-Fig. 1B). This latter observation would be more compatible with a VWD type $2 \mathrm{~A}$ (IIE) but the fact that the mutation is not in the D3 domain does not fit with such a picture. The second sister (II- 1 ) of the proband has a clinicobiological phenotype similar to that of her father.

To understand better the effect of this new p.(Val510 =) variant which appears to be relatively frequent in Martinique, we investigated 21 additional Martinican patients exhibiting the same variant. Patients' characteristics are indicated in - Table 1. Median age was 63 years (interquartile range [IQR], 45-77) and 65\% were female. The striking feature in these patients was a significantly increased VWFpp/VWF:Ag ratio with a median of 5.62 (IQR, 4.36-$6,14)$. Of note, this ratio could be calculated only for the 14 patients for whom the VWFpp level was measured. An increased VWFpp/VWF:Ag ratio ( $>2.2$ ) is indicative of an accelerated clearance of $\mathrm{VWF}^{3}$ To further investigate this potential mechanism, we decided to perform desmopressin (DDAVP) intravenous infusion $(0.3 \mu \mathrm{g} / \mathrm{kg})$ in 4 patients with
Table 1 Clinical and laboratory characteristics of 23 Martinican patients with the p. $($ Val510 $=)$ variant

\begin{tabular}{|l|l|}
\hline Characteristics & $\begin{array}{l}\text { Patients p.(Val510 }=) \\
(n=23)\end{array}$ \\
\hline Age, y & $63(45-77)$ \\
\hline Females (\%) & 65 \\
\hline Blood group non-O (\%) & $30.43^{\text {a }}$ \\
\hline FVIII:C (IU/dL) & $26(17-35)$ \\
\hline VWF:Ag (IU/dL) & $20(16-24)$ \\
\hline VWF:RCo (IU/dL) & $14(10-19)$ \\
\hline FVIII:C/VWF:Ag ratio & $1.4(1-1.67)$ \\
\hline VWF:RCo/VWF:Ag ratio & $0.74(0.5-0.94)$ \\
\hline VWFpp/VWF:Ag ratio & $5.62(4.36-6.14)^{\mathrm{b}}$ \\
\hline
\end{tabular}

Note: Results are indicated as median (25th to 75th percentile) for age, FVIII:C, VWF:Ag, VWF:RCo, FVIII:C/VWF:Ag ratio, VWF:RCo/VWF:Ag ratio, and VWFpp/VWF:Ag ratio. Normal range for VWFpp/VWF:Ag 0.6-1.5.

$\mathrm{a}_{n}=7$.

$\mathrm{b}_{n}=14$. 

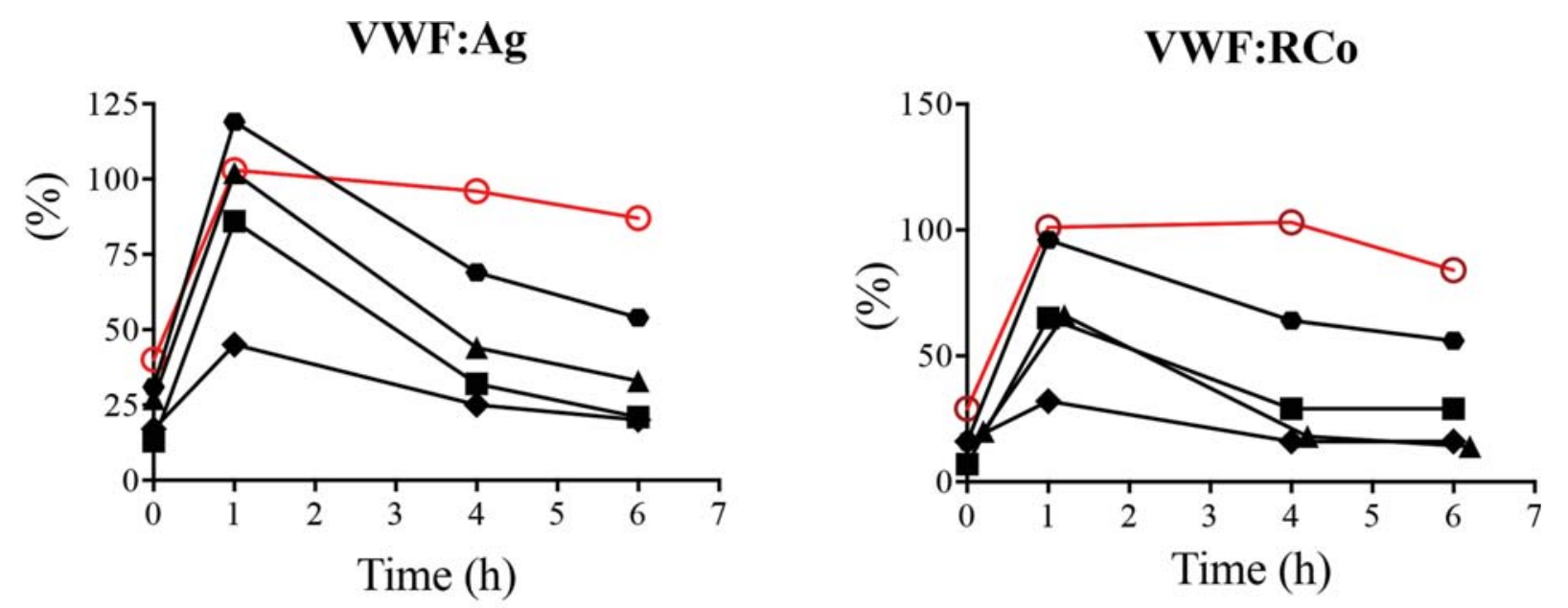

\section{FVIII:C}

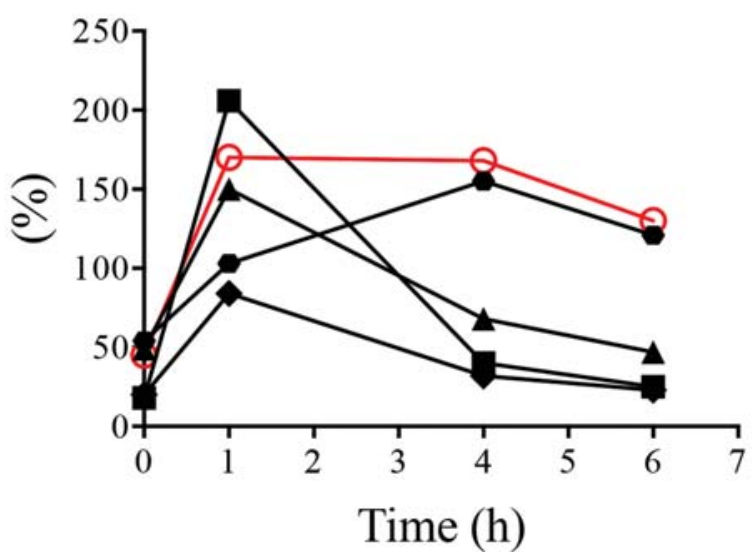

Fig. 2 VWF:Ag, VWF:RCo, and FVIII:C levels after desmopressin (DDAVP) administration. Four patients carrying the p.(Val510 =) variant (black lines) and 1 von Willebrand disease type 1 patient (p.(Pro1413Leu)) were injected with DDAVP. VWF:Ag, VWF:RCo, and FVIII:C were measured at baseline and at 1, 4, and 6 hours post-DDAVP.

the p. $($ Val510 = ) mutation and we measured VWF:Ag, VWF: $\mathrm{RCo}$, and FVIII:C levels at different time points after infusion. The administration of DDAVP prompted a significant increase in VWF:Ag, VWF:RCo, and FVIII:C levels in these 4 patients as well as in a control, a VWD1 patient with the $\mathrm{p}$. (Pro1413Leu) mutation, which does not lead to any clearance defect (-Fig. 2). Sixty minutes after DDAVP injection, the levels of VWF and FVIII:C decreased sharply, returning to baseline levels between 4 and 6 hours post-DDAVP for 3 patients out of 4 carrying the p. $($ Val510 $=)$ mutation. One patient (represented by the black hexagons on the figure) proved to be a better responder to DDAVP than the other 3 patients (despite the same molecular profile). However, even in this patient, VWF:Ag and VWF:RCo decreased quicker than for the control. These results strongly suggest that the p. $($ Val510 $=)$ variant induces an accelerated clearance of VWF.

Another interesting feature associated with this mutation is the difficulty to really assign the patients to a very specific VWD type or subtype. As already mentioned for the father of our original family, the multimeric profile indicates a variable loss of high molecular weight multimers (-Fig. 3) but biological measurements did not show any discrepancy between VWF:Ag and VWF:RCo in most cases. However, since the main effect associated with this mutation appears to be the clearance defect, we propose to classify the patients as belonging to the subtype $1 \mathrm{C}$.

In conclusion, VWF mutational analysis can be valuable for diagnosing and investigating the molecular etiology of VWD. ${ }^{4}$ The prediction softwares used (SpliceSiteFinder-like, MaxEntScan, GeneSplicer, NSPLICE, ESEFinder, RESCUE-ESE, and EX-SKIP) regarding c.1530G $>$ A $(p .($ Val510 =)) interpreted the appearance of a donor site at 6 base pairs at the end of exon 13 which could potentially alter splicing. This synonymous mutation could therefore have an effect on VWF messenger ribonucleic acid processing, causing a shift in the reading frame and the appearance of a termination codon deletion of two codons. The American College of Medical Genetics and Genomics ${ }^{5}$ predicted that this variant would probably be pathogenic. This study contributes to complete 

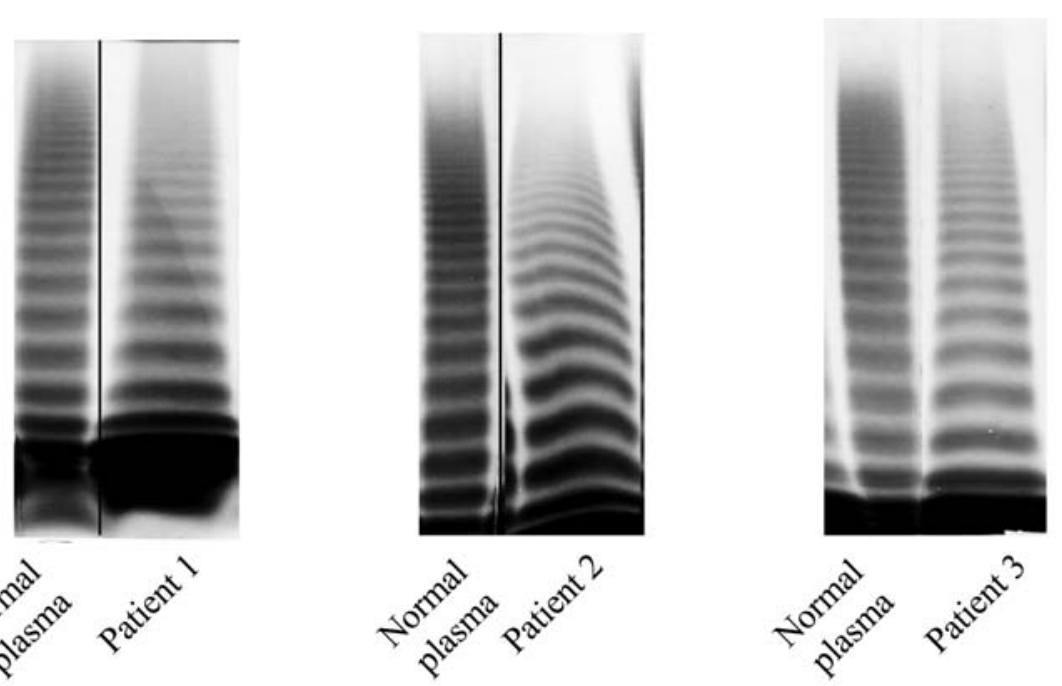

$\begin{array}{cc}\text { VHMWM }>15 & \\ \text { Patient 1 } & 3.7 \% \\ \text { Control } & 9.7 \% \\ \text { HMWM }>10 & \\ \text { Patient } 1 & 10 \% \\ \text { Control } & 23.4 \%\end{array}$

IMW 6 à 10

$\begin{array}{ll}\text { Patient 1 } & 19.6 \% \\ \text { Control } & 27 \%\end{array}$

\section{VHMWM $>15$}

\section{Patient 2}

Control

HMWM>10

Patient 2

$12.2 \%$

Control

$29.2 \%$

IMW 6 à 10

Patient 2

$25.5 \%$

Control

$25.9 \%$

$\begin{array}{rr}\begin{array}{r}\text { VHMWM }>15 \\ \text { Patient } 3\end{array} & 7.5 \% \\ \text { Control } & 13.4 \% \\ \text { HMWM }>10 & \\ \text { Patient 3 } & 18 \% \\ \text { Control } & 28.4 \% \\ \text { IMW 6 à 10 } & \\ \text { Patient 3 } & 23.9 \% \\ \text { Control } & 28.9 \%\end{array}$

Fig. 3 Plasma von Willebrand factor (VWF) multimeric analysis of 3 patients with p.(Val510=). Top panel: Each patient was analyzed on a separate gel and compared with normal human plasma run on the same gel. A black line indicates when the two samples were not run next to each other. Lower panel: Quantification of the multimers was done by densitometry. VHMWM, very high molecular weight multimers ( $>15$ mers); HMWM, high molecular weight multimers (>10 mers); IMW, intermediate molecular weight multimers (6-10 mers).

biological data on VWD, and more particularly on a population of Afro-Caribbean Martinican ancestry.

Note

Human samples were conserved in the Martinique biological bank (CeRBiM).

\section{Funding}

This study was supported by Octapharma France and doctoral scholarships.

\section{Conflict of Interest}

None declared.

\section{References}

1 Doncarli A, Demiguel V, Guseva Canu I, et al; FranceCoag Network. FranceCoag: a 22-year prospective follow-up of the national
French cohort of patients with inherited bleeding disorders. Eur J Epidemiol 2019;34(05):521-532

2 Veyradier A, Boisseau P, Fressinaud E, et al; French Reference Center for vonWillebrand disease. A laboratory phenotype/genotype correlation of 1167 French patients from 670 families with von Willebrand disease: a new epidemiologic picture. Medicine (Baltimore) 2016;95(11):e3038

3 Sanders YV, Groeneveld D, Meijer K, et al; WiN study group. von Willebrand factor propeptide and the phenotypic classification of von Willebrand disease. Blood 2015;125(19):3006-3013

4 Borràs N, Orriols G, Batlle J, et al. Unraveling the effect of silent, intronic and missense mutations on VWF splicing: contribution of next generation sequencing in the study of mRNA. Haematologica 2019;104(03):587-598

5 Richards S, Aziz N, Bale S, et al; ACMG Laboratory Quality Assurance Committee. Standards and guidelines for the interpretation of sequence variants: a joint consensus recommendation of the American College of Medical Genetics and Genomics and the Association for Molecular Pathology. Genet Med 2015;17(05): 405-424 